
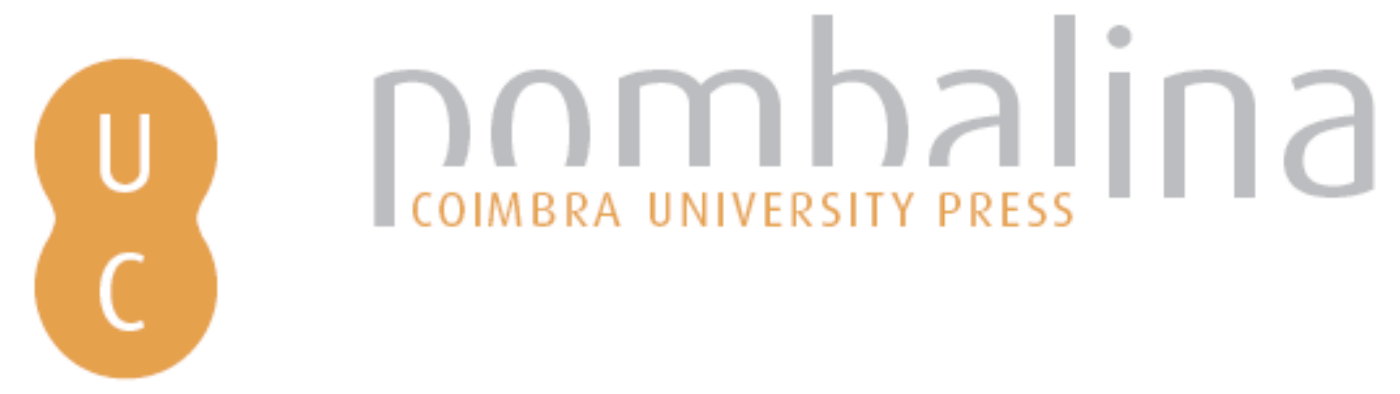

\title{
Proyección política y pedagógica del prólogo a la rethórica de Cicerón dedicado por Alfonso de Cartagena al Infante D. Duarte
}

\author{
Autor(es): $\quad$ González Rolán, Tomás \\ Publicado por: Centro de Estudos Clássicos e Humanísticos; Imprensa da Universidade \\ de Coimbra \\ URL $\quad$ URIstente: $\quad$ URttp:/hdl.handle.net/10316.2/31165 \\ DOI: $\quad$ DOI:http://dx.doi.org/10.14195/978-989-8281-98-2_3 \\ Accessed : $\quad$ 26-Apr-2023 03:36:07
}

A navegação consulta e descarregamento dos títulos inseridos nas Bibliotecas Digitais UC Digitalis, UC Pombalina e UC Impactum, pressupõem a aceitação plena e sem reservas dos Termos e Condições de Uso destas Bibliotecas Digitais, disponíveis em https://digitalis.uc.pt/pt-pt/termos.

Conforme exposto nos referidos Termos e Condições de Uso, o descarregamento de títulos de acesso restrito requer uma licença válida de autorização devendo o utilizador aceder ao(s) documento(s) a partir de um endereço de IP da instituição detentora da supramencionada licença.

Ao utilizador é apenas permitido o descarregamento para uso pessoal, pelo que o emprego do(s) título(s) descarregado(s) para outro fim, designadamente comercial, carece de autorização do respetivo autor ou editor da obra.

Na medida em que todas as obras da UC Digitalis se encontram protegidas pelo Código do Direito de Autor e Direitos Conexos e demais legislação aplicável, toda a cópia, parcial ou total, deste documento, nos casos em que é legalmente admitida, deverá conter ou fazer-se acompanhar por este aviso.

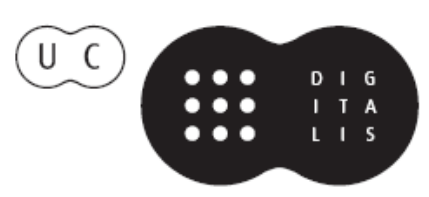


Colecção Autores Gregos e Latinos

SérIe Ensaios

\section{Nair Castro Soares Margarida Miranda Carlota Miranda Urbano}

(Coord.)

HOMO ELOQVENS HOMO POLITICVS

A retórica e a CONSTRUÇão da CIDAdE NA IdAdE MÉdia E NO RENASCIMENTO 


\section{ProyeCción POLÍTICA Y PEDAGÓGICA DEL prólogo a la Rethórica de Cicerón \\ Dedicado por Alfonso de Cartagena al infante D. Duarte}

Tomás González Rolán 
Es bien sabido que después del triunfo de Portugal sobre Castilla en la batalla de Aljubarrota (15- VIII-1385) se respiró un clima de tensión, enfrentamiento y desencuentro entre los dos reinos, sólo en parte mitigado por las treguas generales de 1402 y por la frágil paz de 1411, primer fundamento, según L. Suárez Fernández ${ }^{1}$ de la amistad hispano-portuguesa.

Un paso decisivo en esta dirección fue dado por Juan II al enviar, en 1421, una embajada a Portugal para responder a las que el monarca luso João I había mandado a Castilla en 1418 y 1419. La embajada castellana la componían un prestigioso letrado y jurista, el deán de Santiago Alfonso de Cartagena, futuro obispo de Burgos, y como secretario un noble llamado Juan Alfonso de Zamora, y su misión fundamental era la de entablar la discusión que propiciase la renovación y ratificación de la paz de 1411.

Las negociaciones no fueron fáciles, debido, por un lado, a las exigencias del monarca luso; y por otro, a la firmeza de los representantes castellanos, por lo que duraron mucho tiempo y obligaron a éstos últimos a permanecer en el país vecino en esta primera legación durante un año (diciembre de 1421- diciembre de 1422), y retornados a Castilla para que la tregua fuese firmada por Juan II, regresaron de nuevo después de

\footnotetext{
${ }^{1}$ Fernández, L. Suárez 1960: 37.
} 
Semana Santa de 1423 con el fin de que el acuerdo de paz fuese ratificado por el monarca portugués; volvieron de nuevo en 1424 permaneciendo en Portugal hasta 1425, y finalmente estuvieron en la Corte portuguesa en una cuarta legación entre 1426 y 1427.

La misión política llevada a cabo por Alfonso de Cartagena supuso un rotundo éxito, y en este sentido puede considerarse como un hito en la historia de los encuentros y acercamientos entre Portugal y Castilla en el siglo XV, pues no sólo logró que se firmase la tregua de paz de 1423 sino que propició la paz definitiva, firmada el 30 de octubre de 1431.

A su labor y logros como embajador en la Corte portuguesa se refiere Fernando del Pulgar $^{2}$ en su obra Claros varones de Castilla en los siguientes términos: "fue enbaxador al rey de Portugal por mandado del rey don Juan e, con fuerça de sus razones, escusó la guerra e concluyó la paz que por entonces ovo entre estos dos reinos".

Ahora bien, la ocupación política en defensa de los intereses del reino de Castilla y al servicio de la paz, la completó al establecer una estrecha y fructífera relación cultural no sólo con los miembros de la casa real, sino también con algunos escogidos intelectuales portugueses.

De sus conversaciones con Don Duarte, entonces heredero al trono lusitano, sobre la educación moral del hombre y la formación política de los gobernantes surgieron dos obras realizadas por Alfonso de Cartagena y dedicadas a este príncipe, una de las figuras cimeras,

${ }^{2}$ Pérez Priego, M. Á. (ed.) 2007: 188. 
junto con su hermano el Infante Don Pedro, de la cultura y política portuguesa de la primera mitad del siglo XV, a saber: la obra original titulada Memoriale virtutum, escrita en latín y finalizada en Azoia en el verano de 1422, y la traducción del De inventione de Cicerón, comenzada a petición de D. Duarte en 1424 y terminada algunos años después, posiblemente en 1431- 32. Y si la primera de las obras citadas trata de la ética y formación moral, la Rethórica de M. Cicerón, pues así se llama la traducción del De inventione, viene a completar el marco político del príncipe.

Pero en esta primera legación, no se limitó Alfonso de Cartagena a escribir las obras anteriormente citadas sino que, a petición ahora de su compańero de embajada, Juan Alfonso de Zamora, llevó a cabo la traducción de las obras ciceronianas ${ }^{3}$ De senectute y De officiis y completó el tratado del De casibus virorum illustrium de Boccaccio, dejado aparentemente sin terminar por el Canciller Ayala.

Sobre la influencia, o, si se quiere, la huella dejada por Alfonso de Cartagena en el ambiente intelectual de la corte de Joáo I, hay diversidad de opiniones, pues una historiadora como Isabel Beceiro Pita $^{4}$ sostiene que

"apenas parecen haber tenido eco en Portugal las versiones de Aristóteles, Cicerón y Séneca realizadas por Alonso de Cartagena, que constituyen el máximo exponente del acceso

${ }^{3}$ Cf. Morrás, María (ed.) 1996: 13- 27.

${ }^{4}$ Beceiro Pita, I. 1999: 221- 235, maxime 232. 
de la nobleza castellana a la filosofía clásica y aparecen, de forma reiterada, en las bibliotecas seńoriales de la época",

mientras que otro estudioso, Abdón M. Salazar, en un conocido y muy citado estudio ${ }^{5}$ equipara, sin duda de forma exagerada, el papel de Cartagena en Portugal "difundiendo el entusiasmo por la cultura clásica en Lusitania”, con el que ejerció el bizantino Crisolaras en la Italia de comienzos del Cuatrocientos "diseminando el ideal de la paideia griega entre los latinos".

Ahora bien, ni I. Beceiro Pita ni Abdón M. Salazar han justificado por qué la sabiduría de Alfonso de Cartagena influyó o dejó de influir en la orientación y proyección hacia el Humanismo de la corte portuguesa, tarea que ya en 1925 reclamaba Joaquín de Carvalho ${ }^{6}$, quien refiriéndose a la traducción de la Rethórica dedicada a D. Duarte y antes de reproducir parte del Prólogo, afirmaba que "como fonte da cultura da corte de D. Duarte, merecem transcrever-se o prefácio e a introdução do bispo de Burgos, cujas relações com Portugal exigem um estudo especial”.

El estudio especial de las relaciones de Cartagena con la cultura portuguesa no ofrece, como pensaba Abdón M. Salazar, una sola dirección, a saber, la que lleva de Cartagena a los miembros de la casa real y a los intelectuales portugueses, sino también la recíproca, la que parte de estos últimos y alcanza al eminente letrado y jurista castellano.

${ }^{5}$ Abdón M. Salazar 1976: 215- 226, maxime 217.

${ }^{6}$ Carvalho, Joaquim de 1925: 114-140, maxime 128- 129. 
En efecto, se considera de una gran importancia en la propia orientación cultural de Cartagena el contacto mantenido con un selecto grupo de intelectuales portugueses, que habían estudiado en Bolonia ${ }^{7}$, pues por medio de ellos en el último viaje oficial a Portugal tuvo la oportunidad de conocer varias versiones latinas de textos griegos realizadas por Leonardo Bruni, a saber, los discursos a favor y en contra de Tesifón de Esquines y Demóstenes, respectivamente, y el tratado de San Basilio sobre la lectura de los libros de los gentiles, hecho que el propio Cartagena nos relata en el prólogo de su Liber en la famosa Controversia con el propio Bruni ${ }^{8}$.

$\mathrm{Si}$, como bien ha señalado Adeline Rucquoi ${ }^{9}$, la imagen que se desprende de obras como el Memoriale virtutum y la Rethórica "montre les castillans comme les maitres...de jeunes princes portugais dont les talents dans ces domaines ont frappé leurs interlocuteurs", no es menos cierto que "ces 'maîtres' castillans ont souvent a leur tour appris du Portugal et des Portugais", por lo

${ }^{7}$ Cf. Costa, A. D. de Sousa 1990: 559- 658; Rau, V. 1969: 185206; Idem 1973: 7-28; Bettini, C. 2008: 205- 226. La profesora Nair de Nazaré Castro Soares, en un importante estudio titulado (2002), "O Infante D. Pedro e a cultura portuguesa", Biblos 78: 107-128 [ maxime 112], afirma que fue de gran significado en la definición de los ideales culturales "a influência directa da Itália em Portugal, pelo menos a partir do início do século XIV. Conhecida é a presença de letrados portugueses em Itália entre 1350 e 1450 e o papel desempenhado pelo abade D. Gomes, geral da ordem camalduense e núncio e visitador apostólico dos mosteiros de Portugal, figura de grande prestígio em Florença”.

${ }^{8}$ Cf. T. González Rolán, T. - Moreno Hernández, A. - Saquero Suárez- Somonte, P., 2000: 194- 205.

${ }^{9}$ Rucquoi, A. 2003: 39- 51, maxime 43. 
que a su parecer, que compartimos, "il y a donc une sorte d'egalité dans l'échange".

Respecto a la opinión de I. Beceiro Pita de que apenas parecen haber tenido eco en Portugal las versiones de Aristóteles, Cicerón y Séneca realizadas por Alfonso de Cartagena, ya hemos adelantado que nos parece que no ha sido debidamente justificada, lo que ocurriría si hubiese hecho un detenido cotejo de dichas versiones con distintas obras, bien de los príncipes $\mathrm{D}$. Duarte y D. Pedro, bien de otros intelectuales o literatos portugueses.

Pero antes de abordar este cotejo, el estudio de las relaciones de Cartagena con la cultura portuguesa exige un conocimiento textual y filológicamente exacto de las obras dedicadas a Don Duarte o al menos de los interesantísimos prólogos tanto de la versión original latina, todavía inédita, del Memoriale virtutum, que se nos ha transmitido por medio de cinco testimonios manuscritos ${ }^{10}$, como de la Rethórica, editado con demasiados errores de transcripción por el gran filólogo español Marcelino Menéndez Pelayo ${ }^{11}$ o con significativos defectos por Rosalba Mascagna ${ }^{12}$, razón por la que como apéndice del presente trabajo incluimos una nueva edición de este interesantísimo texto reproduciendo con exactitud ${ }^{13}$ los folios $1^{\mathrm{r}}-5^{\mathrm{r}} \mathrm{del}$

${ }^{10}$ Cf. Campos Souto, M. 2004: 149- 156.

${ }^{11}$ Menéndez Pelayo, M. 1962: 307- 313.

12 Mascagna, Rosalba 1969.

13 Respetamos las particularidades ortográficas y lingüísticas del manuscrito escurialense, si bien hemos introducido algunas regularizaciones de acuerdo con los usos actuales del castellano en 
manuscrito de El Escorial T.II.12, único testimonio que se nos ha conservado de la versión castellana del De inventione ciceroniano realizada por Alfonso de Cartagena a petición del infante Don Duarte.

Una vez establecidos los textos de estas dos obras, el siguiente paso sería comprobar en qué medida han podido influir en la composición del Leal Conselheiro, obra original del propio dedicatorio, Don Duarte, ahora rey de Portugal.

Por lo que se refiere al tratado latino sobre las virtudes, el propio Don Duarte en el capítulo L de su mencionada obra ${ }^{14}$ cita una serie de libros que él ha leído, obran en su poder y han sido tenidos en cuenta a la hora de escribir sobre la prudencia, justicia, templanza y fortaleza, y entre ellos se encuentra el "Memorial das Virtudes que das Heticas d'Aristotilles me ordenau o adayam de Sanctiago", es decir, el Memoriale virtutum, primera de las obras escritas por Cartagena en dos libros, cuyos prólogos y epílogo están dedicados al Infante portugués.

El alcance de la presencia del Memoriale en el Leal Conselheiro no debió ser pequeño, si hacemos caso de lo que nos dice Abdón M. Salazar ${ }^{15}$

lo que se refiere al uso de mayúsculas y minúsculas, a la separación de palabras y al uso de acentos. Sólo en unos pocos casos hemos introducido conjeturas para remediar pequeños errores del copista o para completar términos desaparecidos o que se leen con dificultad a causa de pequeños deterioros producidos en el cuerpo del texto.

${ }^{14}$ Citamos por la edición clásica de Joseph M. Piel 1942: $207-$ 208; cf. también la edición más moderna de Castro, María Helena Lopes de 1999: 200.

${ }^{15}$ Salazar 1976: 223. 
"Compuesto, sin embargo, en diversas épocas de su vida el Leal Conselheiro, dedicado a la reina Leonor de Aragón, debe mucho, en todo caso, a Cartagena y a sus contertulios este amasijo interesante pero heterogéneo...Y dado el objeto específico intentado por el Infante, el estudio de los matices morales anejos al ejercicio de la lealtad, teniendo en cuenta las funciones de las facultades, y las de la voluntad en especial, está claro que el Memoriale virtutum iba a servirle como anillo al dedo para los 98 capítulos de la Parte I”.

No es el momento para afirmar o negar el aserto de Abdón M. Salazar, cuestión que abordaremos junto con la edición crítica y análisis de los dos prólogos y epílogo del Memoriale dedicados a D. Duarte. Lo que nos interesa ahora es detenernos en la obra de Rethórica ciceroniana, traducida por encargo de D. Duarte y cuyo prólogo le fue brindado.

Así como se cita el Memoriale virtutum, como hemos indicado anteriormente, no hay mención alguna en el Leal Conselheiro ni del De inventione ni de la traducción deAlfonso de Cartagena. Con todo, es posible descubrir puntos en común y evidentes coincidencias entre las ideas sobre la traducción apuntadas en el prólogo y los cinco "avysamentos" para traducir bien del latín al romance portugués ("lynguagem”) que aparecen descritos en el capítulo XCIX del Leal Conselheiro.

Respecto a Cartagena, si se analiza en profundidad su labor como traductor de Cicerón primero y más tarde de Séneca, como teórico de la traducción en su 
Liber o Tratado contra Leonardo Bruni ${ }^{16}$, así como sus reflexiones en algunos prólogos, entre los que destacamos el de la Rethórica ofrecido a D. Duarte, se nos presenta como uno de los más antiguos precursores hispanos de la moderna teoría de la traducción, al plantear el problema de ésta como actividad diferenciada según el tipo de textos de que se trate.

Pero Alfonso de Cartagena no se contenta con marcar la línea divisoria que separa la traducción técnica de la literaria, sino que va mucho más allá del análisis onomasiológico de las traducciones para adentrarse en un serio y profundo examen semasiológico de los términos pertenecientes a los lenguajes literario y científico-técnico.

En efecto, así como en la lengua de partida los términos utilizados en los textos literarios y científicos son semánticamente distintos, en el primer caso caracterizados por ser polísémicos y sinónimos de muchos otros de la lengua, en el segundo por todo lo contrario, es decir, por mantener una relación biunívoca y exclusiva con el concepto señalado, Cartagena, piensa, $y$ en este sentido se nos presenta como un estudioso de una extraordinaria penetración, que la traducción literaria puede servirse de términos polisémicos y sinonímicos de la lengua de llegada, lo que no es posible al traductor de textos científicos, pues habrá de usar verba restricta et propriissima, es decir, palabras caracterizadas por su exactitud, concisión y biunivocidad entre la forma y el contenido, y si la lengua de llegada carece de

${ }^{16}$ Cf. González Rolán et alli 2000: 117- 140. 
esas palabras, le estará permitido al traductor, opina con toda razón Cartagena, recurrir al préstamo lingüístico o proceder a la transcripción del vocablo del original.

En la traducción de las obras que no consideraba científico-técnicas no sólo se contentó con llevar a la práctica un método de traducir, el de la conversio ad sententiam, sino que también se ocupó, como podemos observar en la Rethórica de editar cuidadosamente la obra traducida, dividiendo cada uno de los dos libros en títulos, éstos en capítulos, y añadiendo explicaciones y llamadas marginales.

Por otra parte, Cartagena es consciente de que una de las exigencia de la traducción ad sentenciam ("siguiendo el sseso más que las palabras") es traer al autor al lenguaje del lector, otra el de ser fiel al sentido del original sin preocuparse en demasía por los cambios que se produzcan al nivel de los verba, otra, en fin, es conseguir que el texto traducido no sea oscuro, es decir, que "sin trabajo lo pueda entender quien leer lo quisiere" y que mantenga "grant parte del dulçor" del original.

Pues bien, como justamente ha puesto de relieve Aires A. Nascimento en varios y penetrantes trabajos ${ }^{17}$, en la formulación de las cinco reglas o principios planteados por D. Duarte hay

dados que facilmente se deixam aproximar senão mesmo identificar com as reflexóes e com a prática de Cartagena.

${ }^{17}$ Nascimento 1993: 265- 287; Idem 1997: 113- 138; Idem 1999: 41- 70. 
Num dos conselhos finais em que se sugere a colaboração entre dois agentes de tradução parece retratarse a actuação do bispo de Burgos com o seu secretário Juan Alonso de Zamora (com quem executava as traduçóes, ditando um e escrevendo o outro).

Entrevê-se também a própria linguagem do burgalês no procurar um resultado onde prevaleça a clareza, a formosura, a brevidade, através de operaçóes específicas. A insistência no rigor da linguagem e no decoro da mesma são também conteúdos que se registam em Alonso". 18

Así pues, los principios sobre el hecho de traducir en los que se apoya Don Duarte (fidelidad al original, purismo del lenguaje, pertinencia y propiedad de los términos, decoro moral y claridad de exposición) tuvieron su fuente de inspiración en los escritos y charlas de Cartagena, de manera que incluso una de las preocupaciones de éste último, a saber, la de editar y no solamente traducir los textos aparece también en el quinto 'avyamento' del Infante portugués: “E pera esto aproveita muyto parragrafar e apontar bem”.

Este capítulo 99 del Leal Conselheiro nos muestra, por una parte, que el antiguo 'discípulo' de Cartagena ha demostrado un deseo de perfección que le ha llevado a superarse a sí mismo e incluso al propio maestro, proponiendo nada más ni nada menos que unas reglas generales sobre cómo traducir los textos latinos al romance portugués; por otra, que para el príncipe Don Duarte toda teoría debe ir acompañada de la práctica,

${ }^{18}$ Idem 1997:136- 137. 
que queda reflejada en las dos traducciones, en verso y prosa, que propone de otros tantos textos latinos.

El gran pensador y filólogo George Steiner ${ }^{19}$ comentando el esfuerzo de los hombres por lograr en la traducción un compromiso entre 'letra' y 'espíritu', entre 'palabra' y 'significado', cita como pioneros modernos a los franceses Etienne Dolet (Manière de bien traduire d'une langue en autre, de 1540) y Pierre-Daniel Huet (De interpretatione, de 1680), pues, según él, "no por azar los franceses están a la cabeza en lo que concierne a la teoría de la traducción durante esta época" (= siglos XVI y XVII).

Respecto al primer autor, indica que: "los cinco mandamientos del traductor que enuncia Dolet bien podrían remontarse a los gramáticos y retóricos italianos de principios del siglo XVI y, concretamente, hasta Leonardo Bruni".

Si se comparan los cinco "avysamentos" de D. Duarte y los cinco mandamientos de E. Dolet, a pesar de mediar entre ellos una distancia de más de cien ańos, se observan tantos puntos en común que nos inclinarían a pensar que las ideas sobre la traducción de autores peninsulares como Alfonso de Cartagena, Alfonso de Madrigal (El Tostado) y por supuesto el príncipe heredero de Portugal anticipan ideas que luego enarbolarían como suyas los franceses.

No podemos detenernos más sobre esta cuestión, pues debemos apuntar otro interesante aspecto que se puede deducir de los prólogos dedicados por Cartagena

${ }^{19}$ Steiner 1981: 300- 301. 
a D. Duarte. En un breve pero muy enjundioso estudio ${ }^{20}$ Luis Adão da Fonseca ha puesto de manifiesto la necesidad que la dinastía de Avis, iniciada por João I, tuvo de reivindicar para todos sus miembros el carácter de dinastía mesiánica, caracterizada por la ejemplaridad moral de los valores que encarnaban (unión, sabiduría, virtud, deseo de perfección, etc.).

Respecto de Don Duarte, el citado autor ${ }^{21}$ afirma que parece "ter sido este monarca quem iniciou o proceso de construção ideológica do modelo de exemplaridade da família real portuguesa”.

Si esto es así, este proceso no comenzaría, como sostiene Adáo da Fonseca, tras la muerte de João I sino mucho antes, después de la llegada de Alfonso de Cartagena a Portugal, pues él contribuyó no sólo a formar a los hijos mayores del rey sino también a extender, por medio de sus prólogos, la fama, por otra parte bien merecida, de su virtud, sabiduría, inteligencia y deseo de perfección.

${ }^{20}$ Fonseca 2003: 53-61.

${ }^{21}$ Idem, ibidem: 59. 


\section{Anexo I \\ (MANusCrito DE El Escorial, Signatura: T. II. 12)}

/f.1\%/Libro de Marcho Tullio Çiçeron que se llama de la Retórica trasladado de latín en romançe por el muy reuerendo don Alfonso de Cartajena obispo de Burgos a ynstançia del muy esclaresçido prínçipe don Eduarte rey de Portogal

\section{Prólogo en la traslaçión}

Fablando con vos, prínçipe esclaresçido, en materias de sçiençia en que vos bien sabedes fablar, en algunos días de aquel tiempo en que en la vuestra corte por mandado del muy cathólico Rey, mi sseñor, estaua, vino-vos a voluntad de auer la arte de la Rethórica en claro lenguaje, por conosçer algo de las doctrinas que los antiguos dieron para fermoso fablar; e mandástesme, pues yo a esa sazón paresçía aver algunt espaçio para me ocupar en cosas estudiosas, que tomase vn pequeńo trabajo e pasase de latýn en nuestra lengua la Rethórica que Tullio conpuso.

E comoquier que en el estudio d'ella fuy yo tan poco ocupado e despendí tan poco tienpo que, non digo para la trasladar mas aun para entender algo d'ella, me reputaua e reputo ynsufiçiente, pero, acatando al vuestro studioso deseo, començé a poner en obra vuestro mandamiento.

E, començando ocupar en ello la péñola, 
ssobrevino mi partida e quedó a vos, segunt se suele fazer $/ \mathrm{f} .1^{\mathrm{v}} / \mathrm{r}$ en las compras, como por manera de sseñal, una muy pequeña parte del comienço e vino comigo el cargo de lo acá conplir.

E pasaron después tienpos asaz, en que otra obra mucho mayor e de más trabajo e estudio se podiera acabar; mas ésta non se acabó fasta aquí, çierta mente non por oluido nin por menos preçio -ca lo primero fuera torpeza muy grande, lo segundo inmensa presunçión- mas por sobrevenir tales tienpos que a los semejantes estudios otorgaron ferias noctorias; lo qual para mi escusaçión allegar non sé por quales otras mejores nin tan buenas palabras que por aquellas que escrivió sant Bernardo al papa Eugenio en el libro De la consideraçión, diziéndole así:

Membrándome del prometimiento en que so obligado a ty, o muy buen varón papa Eugenio, quiérome librar, siquiera tarde; e vergüença avría yo de la dilaçión si sopiese que en mí ouiera negligençia o menospreçio. Pero non es así, mas sobrevino, commo tu sabes, tienpo graue, tal que al huso de la vida paresçía enbargar quanta más a los estudios.

E parésceme que puedo a propósito dezir algo de lo semejante -non porque entiendo que vino a uos tanta graueza de tienpo commo a él por ventura vino, nin que la presente traslaçión sea de tanto estudio nin requiera tanto trabajo commo la compusiçión que él fazía; mas nin el yngenio e sçiençia de quien esto escriue es egual por çierto, nin ha proporçión nin respecto con la de aquel santo e famoso varón. E así non es de marauillar 
que pequeño /f. $2^{\mathrm{r}} /$ yngenio en la pequeña obra con menor inpedimento tanto se enbargue, commo el grande en la obra más alta por el ynpedimento mayor.

Por ende la tardança que en esto ouo, si la afeçción non me engaña, que suele defender las culpas proprias, non es mucho de culpar. $\mathrm{Ca}$, ocupado nuestro muy ýnclito prínçipe en su graçiosa juventud contra una parte de sus vezinos en defensión de su honor real e anparo de la su república, e contra otra en exaltaçión de la santa fee cathólica e opresión de los enemigos de la vera Cruz, que dentro de los nuestros términos tanto tienpo ha que moran, razonable cosa es que todos sus súbditos, dexadas las otras cosas en que en los otros tienpos se suelen ocupar, bueluan su coraçón enteramente e ocupen su voluntad poniendo su poderío, en quanto el estado e fuerça de cada vno basta, para le en ello seruir.

Pero, entre las otras ocupaçiones, tomé algunt poco espaçio para conplir vuestro mandado e pagar ya esta debda e, llamada la ayuda diuinal, fízelo así como vedes, non tal sin dubda commo fazer se deuía e pertenesçía enbiar a vos a quien se dirige, mas commo la inbeçilidat e flaqueza del yngenio del escriuiente en ta<nto $>$ bastó; confiando en vuestra virtuosa equanimidat que rescebiredes benignamente esta paga, aunque tarde, e tollerando los defectos que en la presente traslaçión fallaredes, donde tollerar se podieren e hemendándolos donde hemendar se deuieren.

E para más clara ver la intençión, ante que oyades a Tullio, oyd la introduçción siguiente /f. $2^{\mathrm{v}} /$ : 


\section{Introducción}

Muchos fueron los que de la rethórica en los tienpos antiguos fablaron, así griegos como latynos. Pero avnque de la eloquençia de asaz d'ellos oy dura la fama e de algunos sus famosas oraçiones, -así commo entre los griegos de Demosten<e >s e de Eschines e entre los latinos de Salustio- e de otros más libros conpuestos de la arte liberal mesma que llaman rethórica, yo non sé que de aquellos muy antiguos en este tienpo parescan, si non de dos actores: el uno griego, el otro latino.

El griego fue Aristotiles, que fabló en ello profundamente: ca non entendió aquel philósopho que del todo acabaua la obra moral, si después de las Éthicas e Políticas non diese doctrinas de lo que a la eloquençia pertenesçe, e conpuso vn libro que se llama de la Rethórica, en que escriuió muchas e nobles conclusiones pertenesçientes a esta arte, de las quales, así por theólogos commo por juristas, son muchas <e en di>versos logares allegadas, cada una a su propósito.

El otro fue latino e éste es Marcho Tullio Çiçerón el qual escriuió muchos libros e tractados de diversas materias, escriptos sso muy eloquente estilo. E entre ellos conpuso algunos pertenesçientes a la doctrina d'esta arte. Ca, aunque en todos guardó él bien las reglas de la eloquençia, pero non fabló en todos d'ella; ca una cosa es fablar segunt la arte e otra es fablar de la arte. E él en todos guardó la arte; pero non en todos mas en algunos fabló de la arte. Éstos si sson /f. $3^{\mathrm{r} / \text { muchos }}$ o quántos son, non lo sé, mas los que común mente 
parescen son los siguientes: el libro de la Rethórica vieja e otro de la Rethórica nueva e un libro que dizen del Orador e otro del Orador menor e un breve tractado que se llama De la muy buena manera de los oradores e otro que se yntitula la Tópica; los quales, avnque por diuersas maneras, todos tienden a dar doctrinas de la eloquençia. E d'estos, porque el de la Rethórica vieja es primero e avn porque fabla más largo, fue por vos escogido para que se posiese en nuestro lenguaje, e fízose así por vuestro mandado.

En la traslaçión del qual non dubdo que fallaredes algunas palabras mudadas de su propria significaçión e algunas añadidas, lo qual fize cuydando que conplía así; ca non es, éste, libro de Santa Escriptura en que es herror añader o menguar, mas es conposiçión magistral fecha para nuestra doctrina. Por ende, guardada quanto guardar se puede la yntençión, aunque la propriedat de las palabras se mude, non me paresce cosa ynco $<$ n>ueniente; ca, commo cada lengua tenga su manera de fablar, si el ynterpretador sigue del todo la letra, nescesario es que la escriptura sea obscura e pierda grant parte del dulçor. Por ende, en las doctrinas que non tienen el valor por la abtoridat de quien las dixo nin han sseso moral nin míxtico, mas solamente en ellas se cata lo que la sinple letra significa, non me paresçe dapńoso retornar la yntençión de la escriptura en el modo del fablar que a la lengua en que se pasa conviene. La qual manera de trasladar aprueua aquel singular trasladador, sant Geronimo, en una solepne epístola que se sobreescrive De la muy buena manera 
/f. $3^{v} /$ del declarar, que enbió a Pamachio, entre otras cosas diziéndole así:

Yo non solamente lo digo, mas aun con libre boz lo confieso, que en la ynterpretaçión de los libros griegos non curo de exprimir vna palabra por otra mas sigo el sseso e efecto, saluo en las Santas Escripturas, porque allí la horden de las palabras trae mixterio.

E esta manera seguí aquí porque más sin trabajo lo pueda entender quien leer lo quisiere; e aun por lo más aclarar, commoquier que en latin está todo junto e non tiene otra partiçión saluo la de los libros -es a saber entre el primero e segundo- pero yo partý cada libro en diversos títulos e los títulos en capítulos según me paresçió que la diversidat de la materia pidía. E donde el vocablo latino del todo se pudo en otro de romançe pasar, fize-lo; donde non se pudo buenamente por otro canbiar, porque a las vezes una palabra latina requiere muchas para se bien declarar e si en cada logar por ella todas aquéllas se ouiesen de poner farían confusa la obra, en el tal caso al primero paso en que la tal palabra ocurrió se fallará declarada. E, aunque después se aya de repitir, non se repite la declaraçión, mas quien en ella dubdare retorne al primero logar donde se nonbró, el qual está en los márgines señalado, e verá su significaçión.

Pero, aunque esto todo se faga, las conposiçiones que son de sçiençia o de arte liberal, para bien se entender, todavía piden estudio porque non consiste la dificultad de la sçiençia tan sólo en la obscuridat del lenguaje, ca si 
así fuese, los buenos gramáticos entenderían qualesquier materias que en latín fuesen escriptas: e /f. $4^{\mathrm{r}} /$ veemos el contrario, ca muchos bien fundados en la arte de la gramática entienden muy poco en los libros de theología e de derecho e de otras sçiençias e artes, aunque son escriptas en latýn, ssy non ouieron doctores d'ellas que los enseñasen. Por ende, aunque esta Rethórica sea traspuesta en llano lenguaje, quien entenderla quisiere cunple que con actençión la lea.

E demás d'esto, es de saber que algunos cuydan que la rethórica toda consiste en dar dotrinas espeçiales para escrivir o fablar o trasmudar o hordenar las palabras, mas non es así; ca, commoquier que d'ella sale la buena hordenança del fablar, pero non es éste su total yntento, ca grant parte d'ella se ocupa en enseñar cómmo deuen persuader e atraer a los juezes en los pleitos e otras contiendas e a las otras personas en otros fechos, quando acaescen.

E quien bien lo quisiere considerar, fallará que el ofiçio que entre nos tienen los juristas que llamamos abogados, ése era prinçipalmente el de los rethóricos antiguos; e lo que éstos oy quieren fazer allegando testos e determinaçiones, los otros fazían diziendo razones fermosas, cada vno en favor de su parte, e a las vezes inserir aquellas pocas leys que entonçe auía. Lo qual bien puede ver quien las famosas oraçiones de aquellos tienpos leyere; ca aquellas dos que en Athenas se fizieron, que ouieron tanta nonbradía que Tullio mesmo les conosce ventaja e sant Gerónimo faze d'ellas en el prinçipal prólogo de la Biblia mençión, la vna fizo 
Echines acusando a Thesifón, la otra Demosten $<\mathrm{e}>\mathrm{s}$ defendiendo al acusado e reacusando al acusador. E muchas de las que de Tullio leemos son fechas acusando a unos e $/ \mathrm{f} .4^{\mathrm{v}} /$ defendiendo a otros, como fazen los abogados solepnes. Por ende quien lo presente leyere non cuyde que fallará escripto cómmo escriua las causas nin cómmo trasporte las palabras: ca, aunque d'ello otros más modernos en tienpo e non de tan alta manera algo escriuieron, pero los prínçipes de la eloquençia e los preçipuos escriptores d'ella en los prinçipales libros non se ocuparon del todo en esto mas dieron sus generales doctrinas para arguyr e responder, para culpar e defender e para mouer los coraçones de los oyentes a sańa o a misericordia o a las otras pasiones que en la voluntad humana cahen; e dende cada uno saque por su yngenio aquello que entendiere que para en lo que quiere fablar cunple.

E d'esto Aristotiles en el libro que deximos fabló muy profunda e sçientíficamente; e Tullio en éste non con tanta sçiençia, mas por más clara e más particular hordenança, dixo algunas cosas notables que del otro tomó e aun añadiendo de suyo -entre las quales hay algunas que, si bien entendidas e a buen fin traýdas son, pueden mucho aprouechar; e si con maliçiosa intençión d'ellas se husa, podrían algo dapñar, mas nin por esto son de dexar; ca el fierro non es de dexar, aunque con él se cometen a las vezes ynjustos omeçidos e muertos a mala verdat, porque las armas fechas d'él aprovechan ha esforçar la justiçia e ha justa defensión de la república e opresión de los ynjustos e malos. 
Nin las doctrinas del especulador e de los otros juristas práticos son de menospreçiar porque con éllas los malos abogados fazen muchas cauilaçiones, pues los buenos ¿dónde toman mucho avisamiento para guiar la justicia /f. $5^{\mathrm{r}} / \mathrm{e}$ oviar a las maliçias que contra ella se tienen?

Por ende, a buen fin e con recta e sana yntençión oyamos ya qué dize Tullio. 


\section{Bibliografia}

Beceiro Pita, I. (1999), "La Recepción de la cultura aristocrática castellana en el Portugal de los Avis", Estudios - Letras 1: 221- 235.

Bettini, Clelia (2008), “Tre Valascos nell'Italia del Quattrocento: Meser Valasco di Vespasiano da Bisticci, Petrus Vallascis di Cataldo Sículo e Vasco Fernandes de Lucena”, Humanitas 60, 2008: 205-226.

Campos Souto, M.(2004), Memorial de virtudes: la traducción castellana del Memoriale virtutum de Alfonso de Cartagena, Burgos, Instituto Municipal de Cultura.

Carvalho, Joaquim de (1925), "A erudição de Gomes Eanes de Zurara (Notas em torno de alguns plágios deste Cronista)", Boletim bibliográfico da Biblioteca da Universidade de Coimbra 7: 114-140.

Castro, María Helena Lopes de ed. (1999), Dom Duarte, Leal Conselheiro. Edição crítica, introdução e notas (prefácio de Alfonso Botelho). Lisboa.

Costa, A. D. de Sousa, O.F.M. (1990), Portugueses no Colégio de S. Clemente e Universidade de Bolonha durante o século XV, vol. I, Bolonia, Publicaciones del Real Colegio de España.

Fonseca, Luis Adão da (2003), "Política e cultura nas relaçóes luso-castelhanas no século XV", 
Peninsula. Revista de Estudos Ibéricos, no 0: 53- 61.

González Rolán, Tomás. - Moreno Hernández, A. - Saquero Suárez- Somonte, Pilar (2000), Humanismo y Teoría de la Traducción en España e Italia en la primera mitad del siglo XV. Edición y estudio de la Controversia Alphonsiana (Alfonso de Cartagena vs. L. Bruni y P. Candido Decembrio), Madrid, Ediciones Clásicas.

Marcelino Menéndez Pelayo, Marcelino (1962), Historia de las Ideas Estéticas en España, Madrid: 489- 494.

Marcelino Menéndez Pelayo, Marcelino (1950), Bibliografía Hispano- latina Clásica, vol. II, Santander, 1950.

Morrás, María (ed.) (1996), Alonso de Cartagena. Libros de Tulio: De senectute, De los Ofiçios. Edición, prólogo y notas, Alcalá de Henares: Universidad.

Nascimento, Aires A. (1993), "As livrarías dos Príncipes de Avis", Biblos 69 (Actas do Congresso Comemorativo do $\sigma^{\circ}$ Centenário do Infante $D$. Pedro: 25 a 27 de Novembro de 1992): 265- 287.

Nascimento, Aires A. (1997), "Traduzir, verbo de fronteira nos contornos da Idade Média”, in $O$ género do texto medieval, Cristina Almeida Ribeiro - Margarida Madureira (coords.), Lisboa: 113-138.

Nascimento, Aires A. (1999), “Os textos clássicos em 
período medieval: tradução como alargamento de comunidade textual", in Raizes greco-latinas da cultura portuguesa. Actas do I Congresso da APEC, Coimbra: $41-70$.

Pérez Priego, Miguel Ángel (ed.) (2007), Fernando del Pulgar, Claros varones de Castilla, Madrid, Cátedra - Letras Hispánicas.

Piel, Joseph M. ed. (1942), Leal Conselheiro o qual fez Dom Eduarte rey de Portugal e do Algarve e Senhor de Cepta. Edição critica e anotada. Lisboa.

RAU, Virgínia (1969), "Italianismos na cultura jurídia portuguesa do século XV", Revista Portuguesa de História 12: 185- 206.

Rau, Virgínia (1973), "Studenti ed eruditi portoghesi in Italia nel secolo XV", Estudos Italianos em Portugal 36: 7-28.

Rosalba Mascagna (1969) Alfonso de Cartagena, La Rethórica de M. Tullio Ciceron. Liguori-Napoli.

RuCQuoI, Adeline (2003), "Rois et princes portugais chez les auteurs castillans du XVème siècle", Peninsula. Revista de Estudios Ibéricos (Entre Portugal e Espanha. Relaçôes Culturais (séculos XV-XVIII). In Honorem Jose Adriano de Freitas Carvalho), no 0: 39- 51.

Salazar, Abdón M. (1976), "El impacto humanístico de las misiones diplomáticas de Alonso de Cartagena en la Corte de Portugal entre Medievo 
y Renacimiento (1421- 1431)”, Medieval Hispanic Studies presented to Rita Hamilton, in A.D. Deyermond (ed.), Londres, 215- 226.

Soares, Nair N. Castro (2002), "O Infante D. Pedro e a cultura portuguesa”, Biblos 78: 107-128.

Steiner, George (1981) Después de Babel. Aspectos del lenguaje y la traducción, México -Madrid - Buenos Aires, Fondo de Cultura Económica.

SuÁrez Fernández, L. (1960), Relaciones entre Portugal y Castilla en la época del Infante Don Enrique, 1399-1460, Madrid, Consejo Superior de Investigaciones Científicas. 